\title{
A Fatal Case of Non-Ischemic Cardiomyopathy due to Secondary Cardiac Hemochromatosis in a Patient with Pure Red Cell Aplasia
}

\author{
Roberto Cerrud-Rodriguez* MD, Diego Alcaraz-Alvarez MD and Roman Castillo MD \\ Department of Internal Medicine, SBH Health System, USA
}

Submission: February 08, 2018; Published: February 28, 2018

*Corresponding author: Roberto Cerrud-Rodriguez, Department of Internal Medicine, SBH Health System, $44223^{\text {rd }}$ Avenue, Bronx, NY, 10457, USA, Tel: 718-960-9000; Email: robertocerrud@gmail.com

\begin{abstract}
A 30-year-old female with a long-standing history of transfusion-dependent red cell aplasia and non-compliance with treatment was admitted with a new complain of shortness of breath. Workup revealed heart failure with reduced ejection fraction (LVEF 15\%) with very high ferritin levels. A cardiac MRI was done due to suspicion of cardiac hemochromatosis, and it showed myocardial iron overload with severe biventricular dysfunction. The patient was stabilized, started on iron chelators and subsequently optimized for discharge, with plans for eventual orthotopic heart transplant after she had shown improved compliance. Two weeks later she was readmitted due to CHF exacerbation and cardiogenic shock. She went into V-fib arrest multiple times soon after being admitted. Patient's family decided not to continue with resuscitation efforts due to futility. This case undermines the importance of patient compliance with treatment and prompt diagnosis in the successful management of cardiac disease.
\end{abstract}

Keywords : Heart failure; Hemochromatosis; Pure red cell aplasia; Cardiac MRI; NICM; Cardiomyopathy

\section{Introduction}

We present for your consideration the case of a 30-year-old female with a history of pure red cell aplasia and transfusiondependency that subsequently developed secondary hemochromatosis due to her non-compliance with chelator therapy. Given the rarity of cardiac hemochromatosis, we thought that sharing the cardiac MRI findings of myocardial iron deposition will increase the knowledge base of our colleagues regarding this condition

\section{Case Report}

This is the case of a 30-year-old female from the Dominican Republic, with history of transfusion-dependent pure red cell aplasia since age 6, (average of 2 transfusions/month), with secondary hemochromatosis (Figure 1) and cirrhosis. She had recently migrated from the Dominican Republic and had a very poor insight of her condition. She had failed multiple therapeutic trials with steroids and cyclosporine as well as chelating therapy due to non-compliance.

The patient had a recent hospital admission during which she was newly diagnosed with advanced CHF. BNP was 7062pg/
$\mathrm{mL}$, Ferritin 30,044ng/mL, Transthoracic ECHO showed severe 4-chamber dilatation, with a left ventricular ejection fraction (LVEF) of $15 \%$ and global LV hypokinesis. Due to suspicion of cardiac hemochromatosis, a cardiac MRI was obtained, showing myocardial iron overload with severe biventricular dysfunction (Figure 2).

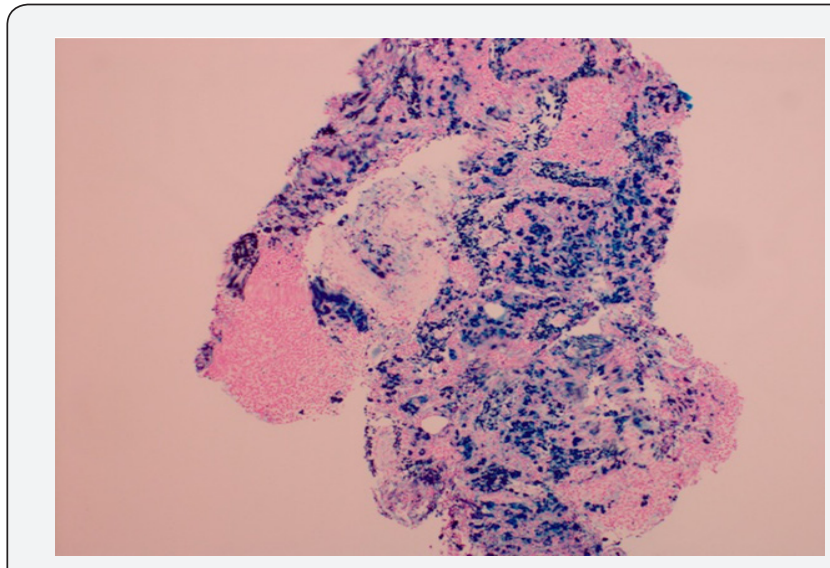

Figure 1: Lymph node biopsy. $4 x$ power. Iron pigments are highlighted by iron stain (blue). 


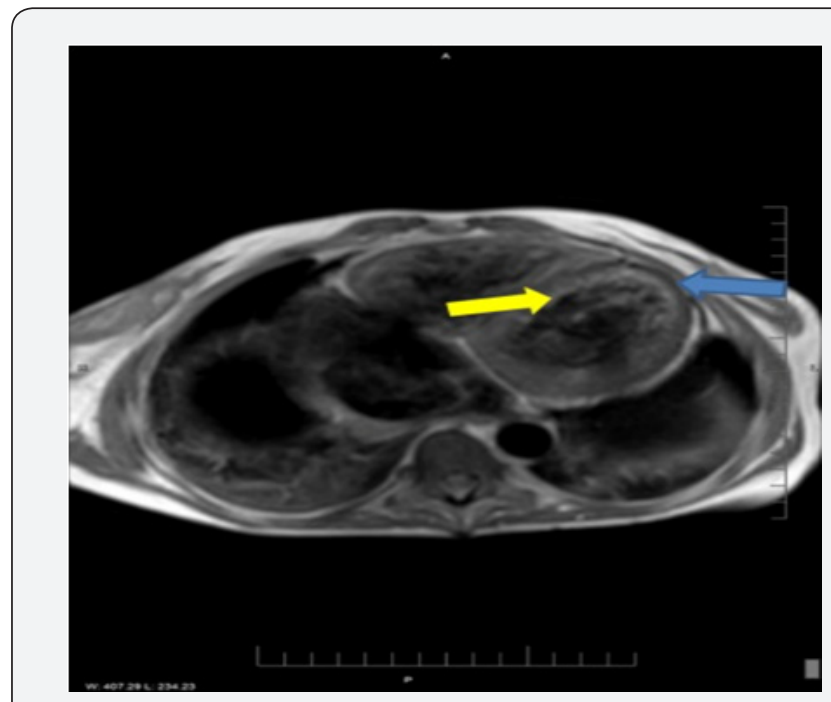

Figure 2: Cardiac MRI in axial black blood sequence with subepicardial (blue) and subendothelial (yellow) signal loss from iron deposition characteristic of cardiac hemochromatosis.

She was seen by the Heart Failure service, who decided to manage her medically, with improvement of her condition. It was determined that advanced CHF therapies were to be considered once the patient had shown improved compliance with therapy. Due to improvement in her overall clinical condition, she was started on deferasirox and discharged home with close follow-up appointments.

Two weeks later, she was readmitted with an exacerbation of $\mathrm{CHF}$ and cardiogenic shock. Her dyspnea made it impossible for her to speak in full sentences, and she was using accessory muscles. Her labs showed severe anemia with a haemoglobin of $4 \mathrm{~g} / \mathrm{dL}$

She was intubated, started on vasopressors and inotropes and transfused. After being admitted to the intensive care unit, her condition quickly deteriorated and she had an episode of sustained ventricular tachycardia followed by ventricular fibrillation resulting in cardiac arrest. ACLS protocol was started and she was defibrillated twice, with return to sinus rhythm and return of circulation (ROSC). Around 1 hour after her first arrest, she had 3 consecutive cardiac arrests with very brief ROSCs after each one.

After she arrested one final time, a member of the team spoke with her relatives, and they decided not to continue further cardiopulmonary resuscitation, as efforts proved futile. The patient was then declared dead.

\section{Discussion}

Secondary hemochromatosis is the abnormal deposit of iron in organs such as the heart, liver, pancreas and lymph nodes [1], which, in the case of our patient, was caused by her life-long dependency on PRBC transfusions due to her underlying illness. Without appropriate chelating therapy, this phenomenon is seen after approximately 10 years following the start of transfusions [2].

Cardiac dysfunction appears late in the course of the disease, in $35-60 \%$ of patients, and it is the cause of death in up to a third of these patients. Microsomal lipid peroxidation can cause fatty degeneration of the myocardium, which is thought to be the underlying mechanism for CHF [3]. The use of advanced cardiac therapies in our patient was precluded by the fact of her late presentation and her history of non-compliance.

Myocardial involvement in patients with secondary hemochromatosis usually presents itself as advanced congestive heart failure and almost always becomes evident after other organs, such as the liver, pancreas and adrenals have been compromised as a consequence of abnormal iron deposition. Survival is determined by the amount of iron deposition in the myocardium $[2,3]$.

There have been reported cases of patients with secondary cardiac hemochromatosis in which the use of iron chelators has improved the ventricular function -therapeutic phlebotomy is contraindicated as these patients tend to have defects of hematopoiesis that causes them to suffer from severe anemia [2].

In patients with advanced heart failure, compliance with therapy is a requirement 'sine qua non' for advanced therapies (such as automatic implantable cardioverters and orthotopic heart transplantation) to be successful.

\section{References}

1. Moriñigo J, Luengo C, Ledesma C, Arribas A, Nieto F, et al. (2001) Taquicardia ventricular y hemocromatosis cardiaca. Revista Española de Cardiología 54(11): 1328-1331.

2. Nishio M, Endo T, Nakao S, Sato N, Koike T (2008) Reversible cardiomyopathy due to secondary hemochromatosis with multitransfusions for severe aplastic anemia after successful nonmyeloablative stem cell transplantation. Int J Cardiol 127(3): 400-401.

3. Nakao M, Toyozaki T, Nagakawa H, Himi T, Yamada K, et al. (2001) Cardiac Dysfunction Because of Secondary Hemochromatosis Caused by Congenital Non-Spherocytic Hemolytic Anemia. Jpn Circ J 65(2): 126-128. 
(C) This work is licensed under Creative (1) Commons Attribution 4.0 License BY DOI: $10.19080 /$ JOCCT.2018.09.555768
Your next submission with Juniper Publishers will reach you the below assets

- Quality Editorial service

- Swift Peer Review

- Reprints availability

- E-prints Service

- Manuscript Podcast for convenient understanding

- Global attainment for your research

- Manuscript accessibility in different formats

(Pdf, E-pub, Full Text, Audio)

- Unceasing customer service

Track the below URL for one-step submission https://juniperpublishers.com/online-submission.php 